University of Nebraska - Lincoln

DigitalCommons@University of Nebraska - Lincoln

Faculty Publications from the Harold W. Manter Laboratory of Parasitology

10-1994

Escherbothrium molinae n. gen. et n. sp. (Eucestoda: Tetraphyllidea: Triloculariidae) in Urotrygon chilensis (Chondrichthyes: Myliobatiformes: Urolophidae) from the Gulf of Nicoya, Costa Rica

Reva Berman

University of Toronto

Daniel R. Brooks

University of Toronto,dnlbrooks@gmail.com

Follow this and additional works at: https://digitalcommons.unl.edu/parasitologyfacpubs

Part of the Parasitology Commons

Berman, Reva and Brooks, Daniel R., "Escherbothrium molinae n. gen. et n. sp. (Eucestoda: Tetraphyllidea: Triloculariidae) in Urotrygon chilensis (Chondrichthyes: Myliobatiformes: Urolophidae) from the Gulf of Nicoya, Costa Rica" (1994). Faculty Publications from the Harold W. Manter Laboratory of Parasitology. 219.

https://digitalcommons.unl.edu/parasitologyfacpubs/219

This Article is brought to you for free and open access by the Parasitology, Harold W. Manter Laboratory of at DigitalCommons@University of Nebraska - Lincoln. It has been accepted for inclusion in Faculty Publications from the Harold W. Manter Laboratory of Parasitology by an authorized administrator of DigitalCommons@University of Nebraska - Lincoln. 


\title{
ESCHERBOTHRIUM MOLINAE N. GEN. ET N. SP. (EUCESTODA: TETRAPHYLLIDEA: TRILOCULARIIDAE) IN UROTRYGON CHILENSIS (CHONDRICHTHYES: MYLIOBATIFORMES: UROLOPHIDAE) FROM THE GULF OF NICOYA, COSTA RICA
}

\author{
Reva Berman and Daniel R. Brooks \\ Department of Zoology, University of Toronto, Toronto, Ontario, Canada M5S 1A1
}

\begin{abstract}
Cestodes collected in spiral valves of the stingray Urotrygon chilensis from the Pacific coast of Costa Rica represent an undescribed species of Tetraphyllidea. By possessing more than 2 loculi as well as an apical sucker on each bothridium, the new species is diagnosably distinct from all other tetraphyllidean genera; therefore, a new genus is proposed for it. The new species also possesses globular structures irregularly arranged on the surface of the bothridia. We found similar structures on the bothridial faces of Trilocularia acanthiaevulgaris, possibly indicating phylogenetic relationships with the new species. This possibility is enhanced by the observation that the bothridia of $T$. acanthiaevulgaris comprise 2 loculi and an apical sucker, rather than 3 loculi.
\end{abstract}

Little is known about the parasite fauna of elasmobranchs inhabiting the Pacific Ocean coast of Central America. During the initial stages of an inventory of the parasite biodiversity of Costa Rican elasmobranchs, stingrays were collected from several locations in the Gulf of Nicoya and the Guanacaste coast. Among the parasites collected were specimens of an undescribed and unusual tetraphyllidean eucestode, which we describe and for which we propose a new genus.

\section{MATERIALS AND METHODS}

Stingrays were collected at night using a beach seine. Cestodes were relaxed in sea water, killed in a relaxed condition with hot water, fixed immediately with AFA, and stored in $70 \%$ ethanol. Whole mounts were stained with Mayer's hematoxylin. Serial cross sections of proglottids and scolices were cut $7 \mu \mathrm{m}$ thick, stained with Mayer's hematoxylin, and counterstained with eosin. Whole mounts and cross sections were mounted in Canada Balsam. All measurements are in micrometers unless otherwise noted $(\mathrm{n}=$ sample size; $\bar{x}=$ mean; $\mathrm{SD}=$ standard deviation). USNM Helm. Coll. refers to U.S. National Museum Helminthological Collection, Beltsville, Maryland.

\section{Escherbothrium n. gen.}

Diagnosis: Eucestoda: Tetraphyllidea: Triloculariidae. Scolex with 4 pedicellated bothridia. Each bothridium with apical sucker and muscular septa dividing adherent surface of bothridia into loculi. Adherent surface of bothridia with irregular number of irregularly spaced spherical protrusions. Ovary X-shaped in cross section.

Type and only species: Escherbothrium molinae.

Received 16 February 1994; revised 25 April 1994; accepted 25 April 1994.

\section{Escherbothrium molinae n. sp.}

(Figs. 1-6, 8)

Description (based on 35 specimens): Strobila craspedote, apolytic, up to $8.2 \mathrm{~mm}$ long $(\mathrm{n}=31, \bar{x}=5.2$, $\mathrm{SD}=1.3)$, composed of 19-39 proglottides $(\mathrm{n}=28, \bar{x}$ $=28, \mathrm{SD}=5.2$ ). Scolex bilaterally symmetrical, with 4 pedicellated, cup-shaped bothridia. Scolex 493-1,019 wide $(\mathrm{n}=31, \bar{x}=748, \mathrm{SD}=112)$. Pedicels contractile, 34-159 long $(\mathrm{n}=103, \bar{x}=83, \mathrm{SD}=24.2)$. Bothridia $306-600$ long $(\mathrm{n}=120, \bar{x}=463, \mathrm{SD}=52.1)$ by 144 344 wide $(n=119, \bar{x}=238, \mathrm{SD}=34.8)$, subdivided by muscular septa into 4 large and 2 small, somewhat triangular, loculi. Longitudinal edges of bothridia with thin, contractile, velum-like membrane veiling bothridial face when relaxed. Bothridial apical sucker on center of anterior edge of velum, 34-103 in diameter ( $\mathrm{n}=114, \bar{x}=66, \mathrm{SD}=10.9$ ). Adherent surface of bothridia with irregular number of irregularly spaced spherical protrusions. Caudal peduncle 141-506 long $(\mathrm{n}=30, \bar{x}=313, \mathrm{SD}=76.5)$. Immature proglottides square to longer than wide. Mature proglottides longer than wide. Terminal attached proglottides tapered posteriorly, 375-1,469 long $(\mathrm{n}=33, \bar{x}=881, \mathrm{SD}=19.5)$ by $109-244$ wide $(n=33, \bar{x}=172, \mathrm{SD}=34.6)$. Internal longitudinal muscles in relatively discrete bundles lying near interior surface of tegument. Testes in 2 longiiudinal preporal fields in anterior $2 / 3$ of proglottis, 1930 in total $(\mathrm{n}=24, \bar{x}=23, \mathrm{SD}=2.8) ; 9-15$ aporal (n $=24, \bar{x}=11.4, \mathrm{SD}=1.5), 9-15$ poral $(\mathrm{n}=24, \bar{x}=$ $11.5, \mathrm{SD}=1.6) ; 29-73$ in diameter $(\mathrm{n}=120, \bar{x}=46$, $\mathrm{SD}=10.2)$. Cirrus sac in posterior $1 / 3$ of proglottis, 38 106 long $(\mathrm{n}=29, \bar{x}=70, \mathrm{SD}=12.4)$ by 23-62 wide $(\mathrm{n}=24, \bar{x}=46, \mathrm{SD}=9.2$ ), containing spined, eversible cirrus. Vas deferens extensively coiled on aporal side of cirrus sac posterior to testes. Genital pores alternating irregularly, $57-75 \%$ of total proglottis length from anterior end of terminal proglottid $(n=25, \bar{x}=$ $62 \%$, SD $=4.2$ ). Genital atrium shallow. Vagina anterior to cirrus sac and posttesticular, passing medially, curving posteriorly around aporal side of cirrus sac and around dorsal side of vas deferens. Vaginal sphincter present. Ovary bilobed, V-shaped in frontal view, $X$-shaped in cross section, 178-438 long $(n=25, \bar{x}=$ 

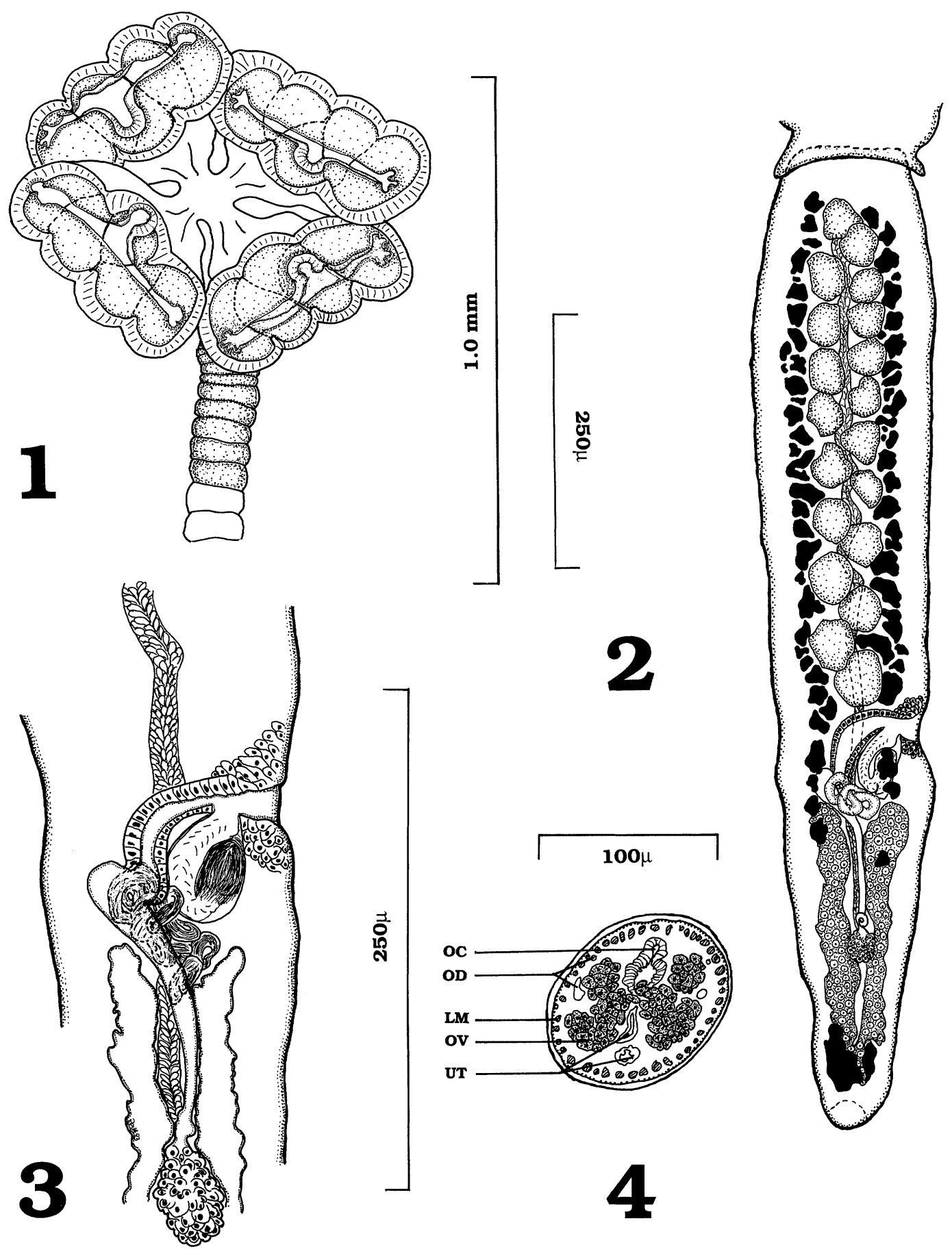

FIGURES 1-4. Escherbothrium molinae n. gen. et n. sp. 1. Scolex. 2. Mature attached proglottis. 3. Terminal genitalia. 4. Cross section of mature proglottis at ovarian isthmus, showing X-shaped ovary (OV), oocapt (OC), osmoregulatory ducts (OD), longitudinal muscle (LM), and uterus (UT). 

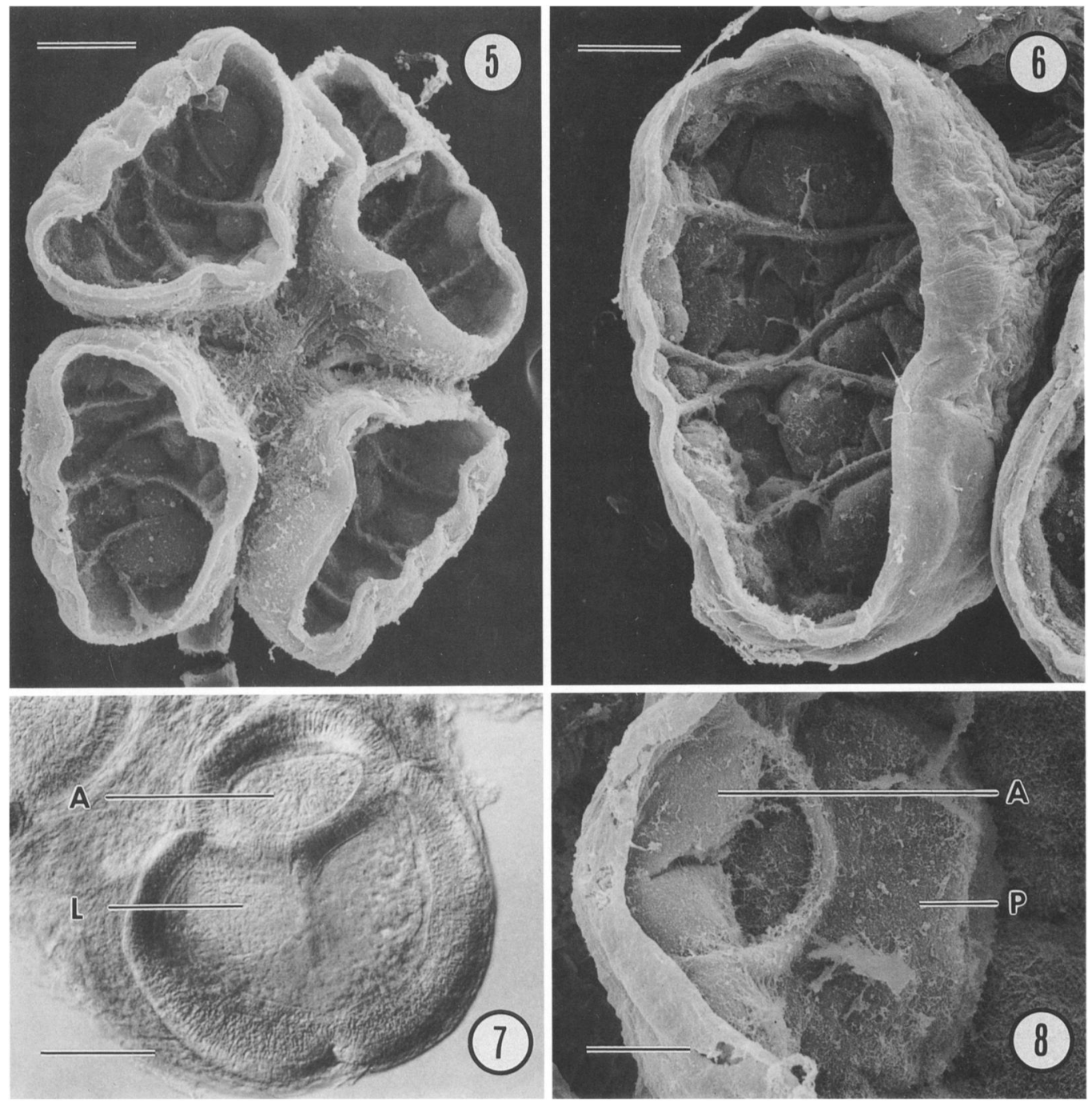

Figures 5-8. Photomicrographs of E. molinae n. gen. et n. sp. and Trilocularia sp. 5-6. Scanning electron photomicrographs of E. molinae n. gen. et n. sp. 5. En face view of scolex. Scale bar $=125 \mu \mathrm{m}$. 6. En face closeup of bothridium showing 6 loculi and numerous rounded protrusions on bothridial surface. Scale bar $=75 \mu \mathrm{m}$. 7. Light photomicrograph of bothridium of Trilocularia sp. (USNM Helm. Coll. no. 7678), showing single anterior apical sucker (A) and two loculi (L). Scale bar $=100 \mu \mathrm{m}$. 8. Scanning electron micrograph of bothridial surface of $E$. molinae, showing apical sucker (A) and rounded protrusions (P). Similar structures appear on the bothridial surface of Trilocularia $\mathrm{sp}$. Scale bar $=25 \mu \mathrm{m}$.

$291, \mathrm{SD}=58.9)$ by $64-130$ wide $(\mathrm{n}=25, \bar{x}=92, \mathrm{SD}$ $=17.9$ ), extending anteriorly to level of posterior extent of cirrus sac. Vitelline follicles medullary, lateral, with follicles dorsal and ventral to osmoregulatory ducts, extending from anterior extent of testicular fields to near posterior end of ovary, interrupted near level of ovarian isthmus; follicles not interrupted near genital pore. Vitelline follicles $6-50$ in diameter $(\mathrm{n}=150, \bar{x}$ $=24, \mathrm{SD}=6.9)$. Gravid detached proglottides not collected.

\section{Taxonomic summary}

Type host: Urotrygon chilensis (Günther, 1871) (Chondrichthyes: Myliobatiformes: Urolophidae).

Type locality: Costa de Pajaros, Gulf of Nicoya, Costa Rica. Other locality: Punta Morales, Gulf of Nicoya, Costa Rica.

Site of infection: Middle $1 / 3$ of spiral valve.

Specimens deposited: Holotype: USNM Helm. Coll. 84064. Paratype: USNM Helm. Coll. no. 84065.

Etymology: The species is named for Helena Mo- 
lina-Ureña, Centro de Investigaciones Marinas y Limnologicos (CIMAR) and Escuela de Biologia, Universidad de Costa Rica. The genus is named for M. C. Escher, in light of the unusual arrangement of bothridial loculi, which reminded us of some of Escher's surrealist drawings.

\section{DISCUSSION}

The Tetraphyllidea, like most eucestode groups, has a long history of classification but suffers from little rigorous phylogenetic examination, especially at levels of higher taxa. Traditional classifications, e.g., Wardle and MacLeod (1952), Euzet (1959), and Yamaguti (1959), recognize 2 major families, the Phyllobothriidae and the Onchobothriidae. These families are diagnosed on the basis of the presence (Onchobothriidae) or absence (Phyllobothriidae) of hooks associated with the bothridia. This scheme has been convenient from a nomenclatural standpoint but is weak phylogenetically because absence of hooks is a pleisomorphic trait (Brooks et al., 1991) and is thus not a robust character upon which to base a grouping (Wiley et al., 1991). By lacking a diagnosing synapomorphy, the Phyllobothriidae (and associated smaller families) as a whole is a paraphyletic collection of taxa of undetermined phylogenetic relationships. Phyllobothriids can be divided into animals that have apical suckers but lack bothridial loculi, e.g., Anthobothrium van Beneden 1850, Calyptrobothrium Monticelli 1893, Clistobothrium Dailey and Vogelbein, 1990, Clydonobothrium Euzet 1956, Crossobothrium Linton 1889, Monorygma Diesing 1863, Orygmatobothrium Diesing 1863, Rhodobothrium Linton 1889, and the Phyllobothrium lactuca species group (see Brooks and McLennan, 1993; Ruhnke, 1993) and species that have bothridial loculi but lack apical suckers, e.g., Caulobothrium Baer, 1948, Dioecotaenia Schmidt 1969, Pentaloculum Alexander 1953, Rhabdotobothrium Euzet, 1953, Rhinebothrium Linton, 1889, Rhinebothroides Mayes, Brooks and Thorson 1981, Trilocularia Olsson 1867, Tritaphros Lönnberg 1889, Zyxibothrium Hayden and Campbell 1981, and the Phyllobothrium centrurum species group (see Brooks and McLennan, 1993). The absence of bothridial loculi is a plesiomorphic trait used to diagnose the first group of phyllobothriids which, like the Phyllobothriidae as a whole, is a paraphyletic collection of taxa of undetermined phylogenetic relationships. The second group, comprised of those taxa that have bothridial loculi but lack bothridial apical suckers (listed above), is a monophyletic group only if the bothridial loculi exhibited by all its taxa are evolutionarily homologous. Some members of the Onchobothriidae, e.g., Acanthobothrium van Beneden 1949, Acanthobothroides Brooks 1977, Calliobothrium van Beneden 1850, and Onchobothrium Blainville 1828, also have bothridial loculi. The assumption that the group exhibiting bothridial loculi is monophyletic must therefore be considered tentative as well, pending the documentation of additional characters indicating phylogenetic relatedness among taxa within this group. To complicate matters further, the paraphyletic nature of the Phyllobothriidae makes the use of members of the Onchobothriidae as outgroups in any phylogenetic analysis of phyllobothriid taxa inappropriate (see Brooks and McLennan, 1991; Wiley et al., 1991). The inherent weakness in the 2-family classification of the Tetraphyllidea may have led Schmidt (1986) to recognize 2 smaller families of phyllobothriids, the Dioecotaeniidae Schmidt, 1969, comprising 1 genus with 2 species which Schmidt removed to its own order, and the Triloculariidae, comprising 3 genera with 4 species.

Escherbothrium molinae, because it lacks bothridial hooks and has bothridial loculi, might appear to be a member of the second group of phyllobothriids discussed above. The presence of both bothridial loculi and apical suckers, however, makes Escherbothrium diagnosably distinct from all other tetraphyllidean genera and suggests that it might represent a phylogenetically transitional form between some members of the nonseptate phyllobothriids (which have apical suckers) and the septate phyllobothriids (which lack apical suckers). We therefore propose a new genus to accommodate $E$. molinae.

No other tetraphyllideans are currently described as having both apical suckers and septate bothridia. Members of the genus Trilocularia Olsson 1867 have been diagnosed as having bothridial faces divided into 3 loculi, e.g., Schmidt (1986). Published line drawings of Trilocularia specimens, e.g., Hyman (1951), Euzet (1959), and a scanning electron microscopic (SEM) study by McCullough and Fairweather (1983), show bothridia with 2 large posterior loculi and an anterior smaller structure which McCullough and Fairweather (1983) termed a loculus. Rees (1953) described the scolex morphology of Trilocularia as including a bothridium divided into 2 loculi with an apical sucker "lying immediately in front of the bothridium," concurring with earlier ob- 
servations (Southwell, 1925). We examined specimens of Trilocularia sp. (USNM Helm. Coll. nos. 7678 and 7679) and concur with Rees (1953) that the bothridia comprise 2 loculi and an apical sucker (Fig. 7). Therefore, we believe that E. $\mathrm{mol}$ inae actually represents the second known tetraphyllidean group possessing apical suckers and loculi associated with the bothridia. The shared retention of a plesiomorphic trait, the apical sucker, is not sufficient to suggest any particular hypothesis of phylogenetic relationships between Escherbothrium and Trilocularia. The specimens of Trilocularia and E. molinae that we examined, however, possess rounded protrusions on the inner bothridial surface (see Fig. 8 for E. molinae). This is a feature that we have not observed or found reported for other tetraphyllideans and which might, therefore, be synapomorphic for Trilocularia and Escherbothrium. If so, the trait might constitute robust grounds for recognizing the Triloculariidae as a group distinct from other phyllobothriids. In addition, 1 of the electron photomicrographs of McCullough and Fairweather (1983) depicts a relaxed bothridium of Trilocularia acanthiaevulgaris, which is highly reminiscent of those of Escherbothrium. Trilocularia species, however, differ from $E$. molinae in a number of characteristics, including having posteriorly positioned genitalia and genital pores and dense spines covering the anterior surface of proglottides (Euzet, 1959).

Schmidt (1986) placed Zyxibothrium Hayden and Campbell, 1981 and Pentaloculum Alexander, 1963 in the Triloculariidae. We examined the holotype and paratypes of Zyxibothrium (USNM Helm. Coll. nos. 75906, 75907-8). There is a marked similarity in the bifurcating structure of the medial bothridial septa of Escherbothrium and Zyxibothrium, although Zyxibothrium lacks apical suckers or rounded protrusions on the inner bothridial surface. We have not been able to obtain any specimens of Pentaloculum for examination, but published illustrations of the scolex depict bifurcating bothridial septa similar to those of Zyxibothrium and Escherbothrium. We thus place Escherbothrium in the Triloculariidae, pending phylogenetic analysis of the group.

Finally, E. molinae is a parasite of eastern $\mathrm{Pa}-$ cific Ocean tropical stingrays, whereas Trilocularia inhabits sharks and Zyxibothrium skates from the northeastern Atlantic Ocean and Pentaloculum inhabits sharks from the western $\mathrm{Pa}$ cific Ocean (New Zealand). Such a wide geographic and host range may indicate that
Escherbothrium, Trilocularia, Zyxibothrium, and Pentaloculum appear closely related to each other only relative to tetraphyllidean species known at this time.

\section{ACKNOWLEDGMENTS}

We gratefully acknowledge Helena Molina Ureña, Escuela de Biologia, Universidad de Costa Rica, for her generous logistical help, assistance in the field, and friendship. We thank Nathan Lovejoy and Effie Gournis for their help in collecting hosts and parasites, Dr. Jose Vargas, vice-director of the Centro de Investigaciones del Mar y Limnologicos (CIMAR), and the staff of the CIMAR laboratory at Punta Morales for the kind use of their facilities, and for technical support in collecting hosts, and the members of the faculty of the Escuela de Biologia and Escuela de Microbiologia, Universidad de Costa Rica. We thank Henry Hong of the Zoology Department, University of Toronto for his help with the SEM portions of this study. This study was funded by operating grant A7696 from the Natural Sciences and Engineering Council (NSERC) of Canada to D.R.B.

\section{LITERATURE CITED}

Brooks, D. R., E. P. Hoberg, AND P. J. WeEkES. 1991. Preliminary phylogenetic systematic analysis of the major lineages of the Eucestoda (Platyhelminthes: Cercomeria). Proceedings of the Biological Society of Washington 104: 651-668.

- AND D. A. MCLenNan. 1991. Phylogeny, ecology and behavior: A research program in comparative biology. University of Chicago Press, Chicago, Illinois, $434 \mathrm{p}$.

— AND — 1 1993. Parascript: Parasites and the language of evolution. Smithsonian Institution Press, Washington, D.C., 429 p.

EuzET, L. 1959. Recherches sur les cestodes tetraphyllides des selaciens des côtes de France. Theses de Ph.D. Faculté des Sciences, Université de Montpellier, Montpellier, France, 263 p.

HYMAN, L. H. 1951. The invertebrates, Vol. II. Platyhelminthes and rhynchocoela. The acoelomate Bilateria. McGraw-Hill Book Company Inc., New York, New York, 550 p.

MCCULLOUGH, J. S., AND I. FAIRWEATHER. 1983. An SEM study of the cestodes Trilocularia acanthiaevulgaris, Phyllobothrium squali and Gilquinia squali from the spiny dogfish. Zeitschrift für Parasitenkunde 69: 655-665.

REES, G. 1953. Some parasitic worms from fishes off the coast of Iceland. Parasitology 43: 4-14.

RuHNKE, T. 1993. A new species of Clistobothrium (Cestoda: Tetraphyllidea), with an evaluation of the systematic status of the genus. Journal of Parasitology 79: 37-43.

SCHMIDT, G. D. 1986. Handbook of tapeworm identification. CRC Press, Boca Raton, Florida, 675 p. 
Southwell, T. 1925. A monograph on the Tetraphyllidea with notes on related cestodes. University Press of Liverpool (Limited), London, U.K., 368 p.

Wardle, R. A., AND J. A. MacLeod. 1952. The zoology of tapeworms. University of Minnesota Press, Minneapolis, Minnesota, $780 \mathrm{p}$.

Wiley, E. O., D. Siegel-Causey, D. R. Brooks, AND
V. A. FUNK. 1991. The compleat cladist: A primer of phylogenetic procedures. University of Kansas Museum of Natural History Press, Lawrence, Kansas, 158 p.

Yamaguti, S. 1959. Systema helminthum, Vol. II. The cestodes of vertebrates. Interscience Publ., New York, New York, 860 p. 